DOI: https://doi.org/10.11144/Javeriana.umed61-3.epep

\title{
Relación entre la enfermedad periodontal y la enfermedad pulmonar obstructiva crónica: revisión de la literatura
}

\section{Relationship between Periodontal Disease and Chronic Obstructive Pulmonary Disease: Review of the Literature}

Recepción: 30/10/2019 | Aceptación: 06/12/2019

\author{
AndRÉs-Felipe Bolaños \\ Facultad de Salud, Universidad del Valle, sede Cali, \\ Colombia \\ JuAN-José JARAMILLO \\ Facultad de Salud, Universidad del Valle, sede Cali, \\ Colombia \\ Alexandra Jiménez \\ Facultad de Salud, Universidad del Valle, sede Cali, \\ Colombia \\ FReddy Moreno \\ Facultad de Salud, Universidad del Valle, sede Cali, \\ Colombia. Facultad de Ciencias de la Salud, Pontificia \\ Universidad Javeriana, sede Cali, Colombia \\ SAndra Moreno-Correa ${ }^{\mathrm{a}}$ \\ Facultad de Salud, Universidad del Valle, sede Cali, \\ Colombia. Facultad de Ciencias de la Salud, Pontificia \\ Universidad Javeriana, sede Cali, Colombia
}

a Autora de correspondencia:

sandra.m.moreno@correounivalle.edu.co

Cómo citar: Bolaños A-F, Jaramillo J-J. Jiménez A, Moreno F, Correa S M. Relación entre la enfermedad periodontal y la enfermedad pulmonar obstructiva crónica: revisión de la literatura. Univ. Med. 2020;61(3). https://doi.org/10.11144/Javeriana. umed61-3.epep

\section{RESUMEN}

Introducción: La enfermedad periodontal (EP) afecta los tejidos de soporte del diente y genera una manifestación inflamatoria persistente, desencadenada por bacterias incluidas en la biopelícula oral, las cuales pueden migrar a otros tejidos del cuerpo, siendo las vías respiratorias un blanco susceptible.

Objetivo: Establecer si existe una relación entre la EP y la enfermedad pulmonar obstructiva crónica (EPOC) según lo reportado en la literatura en los últimos veinte años.

Materiales y métodos: Búsqueda sistemática de la literatura en Medline mediante las pautas de la declaración PRISMA con ayuda de los descriptores en salud tipo MeSH periodontitis, chronic obstructive pulmonary disease, inflammation y bacteremia.

Resultados: Se revisaron 49 publicaciones entre 1998 y 2018. El mayor número corresponde al 2013. El tipo de publicación más frecuente corresponde a los estudios de tipo descriptivo (41\%), seguido por casos y controles (29\%), revisiones de la literatura (18\%), estudios de cohorte retrospectivos $(10 \%)$ y metanálisis $(2 \%)$. Del total de publicaciones, el 94 \% indica que sí existe relación entre EP y EPOC; mientras que el 6 \% niega dicha asociación.

Conclusión: Se encuentra asociación entre las dos enfermedades, aunque la evidencia es insuficiente para establecer una relación causa-efecto. Se 
puede sugerir que la EP es un indicador de riesgo para EPOC y viceversa, ya que se sugiere una relación de doble vía.

Palabras clave

periodontitis; enfermedad pulmonar obstructiva crónica; inflamación; bacteremia.

\begin{abstract}
Introduction: Periodontal disease affects the supporting tissues of the tooth generating a chronic inflammatory manifestation triggered mainly by bacteria included in an oral biofilm, which can migrate to other tissues of the body, the airways being a susceptible target.

Objective: To determine if there is a cause-effect relationship between periodontal disease and chronic obstructive pulmonary disease, as reported in the literature in the last 20 years.

Materials and methods: A systematic search of the literature was performed in Medline (through the PubMed search engine) using the guidelines of the PRISMA declaration with the help of the referred keywords.

Results: 49 publications were reviewed between 1998 and 2018. The largest number corresponded to the year 2013. The most frequent type of publication was descriptive studies (41\%), followed by cases and controls (29\%), reviews of the literature $(18 \%)$, retrospective cohort studies (10\%) and meta-analysis (2\%). Of the total number of publications, $94 \%$ report that there is a relationship between periodontal disease and chronic obstructive pulmonary disease, while $6 \%$ deny such association.

Conclusion: There is an association between the two diseases, although the evidence is insufficient to establish a cause-effect relationship, it can be suggested that periodontal disease is a risk indicator for chronic obstructive pulmonary disease and vice versa, since a twoway relationship is suggested.

Keywords

periodontal disease; chronic obstructive pulmonary disease; inflammation; bacteremia.
\end{abstract}

\section{Introducción}

Durante la última década se han realizado numerosos estudios para comprender la relación entre la enfermedad periodontal (EP) y las enfermedades respiratorias. Esto se debe a que la boca es el sitio anatómico con contacto más frecuente con diferentes tipos de microrganismos que pueden potencialmente infectar la vía gastrointestinal y respiratoria (1). La EP es una enfermedad inflamatoria crónica que afecta los tejidos y las estructuras de soporte del diente y se manifiesta como una amplia variedad de condiciones que afectan el periodonto (es decir, el ligamento periodontal), el cemento dental y el hueso alveolar (2-3). La EP es una de las enfermedades infecciosas más comunes, por ser una alteración de etiología multifactorial con una prevalencia general del $10 \%$ al $90 \%$ en adultos, dependiendo de los criterios diagnósticos $(2,3,4$, 5).

La enfermedad pulmonar obstructiva crónica (EPOC) se define como una limitación en el flujo del aire por excesiva producción de esputo, progresiva e irreversible, caracterizada por una respuesta inflamatoria de los pulmones que puede manifestarse con bronquitis o enfisema (6). Esta patología es más frecuente después de los 50 años de edad y se asocia con factores ambientales. Entre los factores de riesgo para EPOC se incluyen la exposición prolongada al cigarrillo y la exposición continua a toxinas de contaminantes presentes en la atmósfera, además de factores hereditarios (6).

La asociación entre EP y las enfermedades respiratorias se ha establecido por la aspiración prolongada de microrganismos periodontales desde la orofaringe hacia la vía aérea inferior. Uno de los principales patógenos relacionados con la severidad y progresión de la EP es Porphyromonas gingivalis (7), una bacteria que se ha encontrado en el esputo de pacientes con EPOC. Esto se ha comprobado debido al aumento de anticuerpos anti-P. gingivalis en pacientes con mayor frecuencia de episodios de exacerbación (8). Además, se ha observado que el tratamiento de la EP reduce la carga microbiológica, lo que ha sido relacionado con una mejoría en la función pulmonar de los pacientes (9). Teniendo en cuenta lo anterior, se considera la falta de higiene oral un factor de riesgo para el empeoramiento, las complicaciones y la severidad de la EPOC. Por lo tanto, esta revisión de la literatura tiene como objetivo establecer si existe una relación entre la EP y la EPOC según la literatura sobre el tema de los últimos 20 años. 


\section{Materiales y métodos}

Se realizó una búsqueda sistemática de la literatura acerca del tema en la base de datos de la Biblioteca Nacional de Medicina de los Estados Unidos (a través del motor de búsqueda PubMed), mediante las pautas de la declaración PRISMA (10) y los descriptores en ciencias de la salud periodontal disease, chronic obstructive pulmonary disease, inflammation y bacteremia, obtenidos del Medical Subject Headings (MeSH), combinados entre sí con el operador boleano AND. Se tuvieron en cuenta diferentes tipos de estudios, entre los cuales se encontraron estudios descriptivos, casos y controles, estudios de cohorte retrospectivos, revisiones de la literatura y metanálisis, realizados en humanos y publicados entre 1998 y 2018 (ventana de 20 años). Inicialmente, se identificaron 106 artículos y de estos se seleccionaron 90 artículos al filtrar la búsqueda por "humanos". Luego, se eligieron 86 artículos al aplicar el filtro "idiomas" (inglés y español). Por último, se incluyeron 49 artículos que respondieron la pregunta de investigación “iexiste relación entre EP y EPOC?" (figura 1, anexo 1).

\section{Figura 1.}

Diagrama de flujo de la búsqueda de artículos de acuerdo con la metodología PRISMA (10)

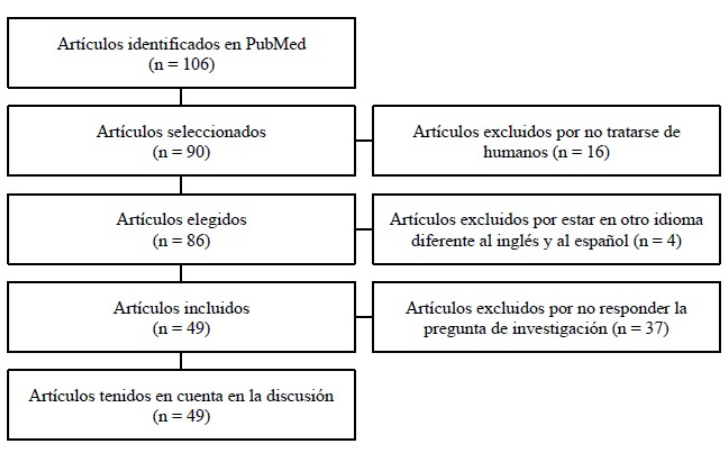

\section{Resultados}

El análisis bibliométrico de los 49 artículos incluidos en esta revisión permitió identificar que la mayoría se publicaron en el 2003 con 9 artículos, seguido por el 2012 y el 2014, con 7 artículos por cada año (figura 2).

\section{Figura 2.}

Cantidad de artículos por año de publicación

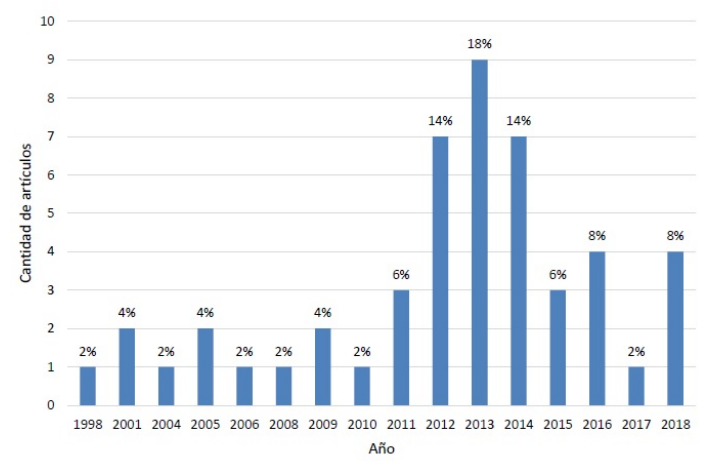

Asimismo, el mayor número de artículos corresponde a 20 estudios observacionales de tipo descriptivo, seguido por 14 de tipo casos y controles, 9 revisiones de la literatura, 5 de tipo cohorte retrospectivos (uno de ellos transversal a partir de un estudio de cohorte retrospectivo) y un metanálisis (figura 3).

\section{Figura 3.}

Cantidad de artículos por tipo de estudio

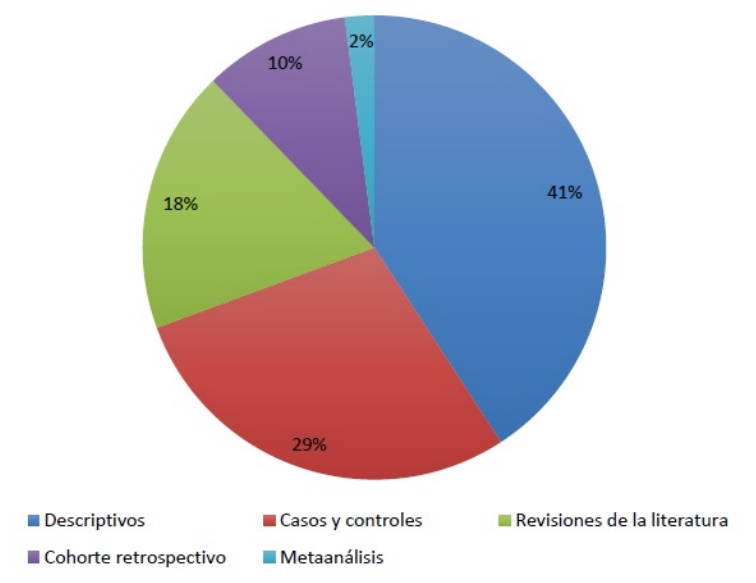

Respecto al país donde se realizó el estudio, 11 artículos resultaron procedentes de China, 9 de Estados Unidos, 7 de India, 3 de Turquía, correspondientes al $62 \%$ de las publicaciones. Irlanda del Norte, Japón, Croacia y Noruega aportaron dos artículos cada uno, para un total del $16 \%$; mientras que México, Alemania, Corea, Reino Unido, Grecia, Inglaterra, Suecia, 
Hungría, Canadá, Polonia y diferentes países del norte de Europa (Noruega, Suecia, Dinamarca, Islandia y Estonia) aportaron un artículo cada uno, para un $22 \%$ (figura 4).

\section{Figura 4.}

Cantidad de artículos por país donde se realizó el estudio

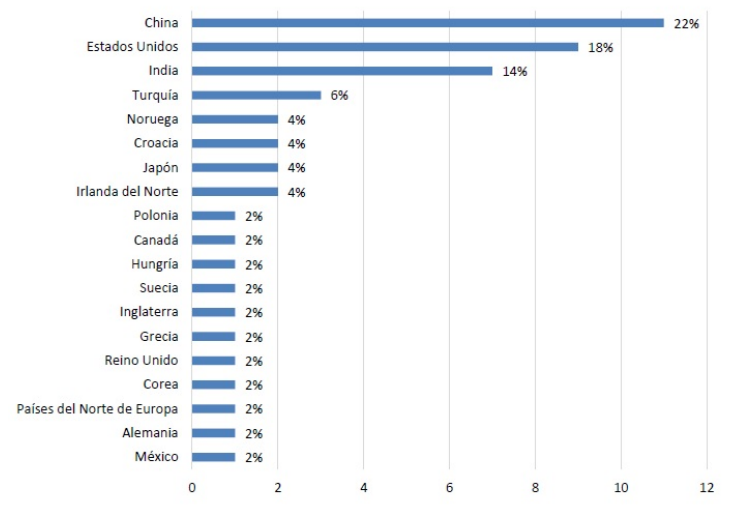

Finalmente, respecto a la pregunta de investigación, de los 49 artículos incluidos en esta revisión, 46 (94\%) concluyeron que sí existe relación entre EP y EPOC; mientras que para 3 (6\%) artículos no hay evidencia suficiente que permita relacionar las dos enfermedades.

\section{Discusión}

En esta revisión de la literatura se analizaron las publicaciones de los últimos 20 años (1998 a 2018) sobre la relación existente entre EP y EPOC. La discusión se realizó de acuerdo con el tipo de estudio de cada uno de los artículos incluidos. Los objetivos y las conclusiones de las publicaciones permiten aproximarse al panorama general de las variables implicadas en esta relación y la importancia de estudiarlas, evaluarlas y comunicarlas en favor del manejo de ambas enfermedades y la prevención de sus complicaciones.

\section{Revisiones de la literatura}

En las revisiones de la literatura que se han publicado se analizó la vía a través de la cual se puede relacionar la EP con enfermedades respiratorias como la EPOC. En la revisión de Felton (11) se muestra que el edentulismo está relacionado con eventos sistémicos dentro de los que podría clasificarse la EPOC. Es importante tener en cuenta que la EP afecta los tejidos de soporte del diente y es una causa importante de pérdida dental y edentulismo (2,3). Es posible relacionar estos procesos con deficiencias en la higiene oral, que favorece la colonización de microrganismos patógenos, los cuales pueden migrar a diferentes zonas anatómicas. Olsen (12) concuerda con lo anterior, y afirma que las bacterias periodontales participan en infecciones extraorales, como enfermedad cardiovascular, diabetes, adenomatosis pulmonar ovina, preeclampsia, EPOC, neumonía, artritis reumatoide, insuficiencia renal crónica, obesidad, cáncer y deterioro cognitivo; sin embargo, se podría presentar una relación opuesta, tal y como lo reportó Devlin (13), quien concluyó que la EPOC produce disnea en los pacientes, lo cual afectaría su cuidado dental de rutina, siendo este un factor importante para evitar el desarrollo de la EP y la exacerbación de la enfermedad pulmonar. Por su parte, Bansal et al. (14) y Azarpazhooh y Leake (15) sugieren que la mejora de la higiene oral es capaz de reducir el riesgo de infección respiratoria y que la atención bucodental profesional frecuente reduce la progresión o aparición de enfermedades respiratorias.

Con lo señalado por los diferentes autores, se considera que el $100 \%$ de las revisiones de la literatura incluidas en este artículo concluyen que existe una relación entre la EP y los microrganismos que hacen parte de la biopelícula, con la EPOC, considerándose estos factores importantes en la frecuencia de las exacerbaciones. No obstante, publicaciones como la de García et al. (16) muestran en sus conclusiones que la relación entre el estado de salud periodontal y el riesgo de EPOC, aunque es biológicamente plausible, sigue siendo especulativa, y sugieren que se requieren ensayos clínicos controlados aleatorios para comprender mejor las bases biológicas de estas asociaciones epidemiológicas. Aunque este tipo de estudios 
genera el nivel de evidencia más alto cuando se relacionan dos enfermedades, hasta el momento no se han publicado estudios de este tipo para relacionar las dos entidades clínicas descritas.

\section{Estudios observacionales}

Desde hace dos décadas aproximadamente, los estudios observacionales descriptivos han demostrado la relación entre la EP y la disminución de la función pulmonar. Prueba de ello son los 20 artículos de tipo descriptivo incluidos en esta revisión de la literatura, de los cuales el $90 \%$ concluyó que hay asociación entre las dos enfermedades (aunque no de tipo causaefecto); mientras que el $10 \%$ indicó que no existe tal asociación. Hayes et al. (17) concuerdan con estas conclusiones, al encontrar en su estudio que pacientes mayores de 42 años presentaron un aumento de la pérdida ósea alveolar radiográfica, lo cual se asoció con un mayor riesgo de EPOC. Adicional a esto, fueron incluidos pacientes con historial de hábito de consumo de tabaco para estudiar su efecto. Según lo expuesto en el trabajo investigativo de Katancik et al. (18), la relación entre EP y la obstrucción de vías respiratorias resulta evidente, especialmente en exfumadores.

Otras publicaciones refirieron una conexión significativa entre la periodontitis marginal crónica y la EPOC grave, que parece ser independiente de los posibles factores de riesgo para la periodontitis, según lo indicaron Leuckfeld et al. (19). En un estudio posterior, Deo et al. (20) demostraron que el riesgo de EPOC parece estar significativamente elevado al encontrar grave pérdida de inserción de los tejidos periodontales, lo cual fue confirmado por Sharma y Shamsuddin (21), Zhou et al. (22) y Vadiraj et al. (23).

Por otro lado, Leuckfeld et al. (24) identificaron la presencia de la especie Veillonella parvula subgingival en los pulmones; sin embargo, no relacionaron esta bacteria con EP o EPOC. En contraste con estos estudios, los autores ya mencionados, Deo et al. (20) y Zhou et al. (22), habían propuesto la importancia de promover el cuidado dental y considerarlo una estrategia de salud pública para reducir la gravedad de la infección pulmonar en poblaciones susceptibles, al mejorar la calidad de vida en pacientes con EPOC, pues se asume la microbiota como un elemento importante en esta relación. Takahashi et al. (25) sugirieron que medir los títulos de anticuerpos para microrganismos periodontales específicos como $P$. gingivalis (títulos de $\operatorname{IgG}$ ) sería de gran utilidad para identificar pacientes con susceptibilidad a exacerbaciones, utilizando esta prueba como estrategia preventiva. Barros et al. (26) encontraron que el riesgo de eventos relacionados con EPOC, después de ajustar los potenciales factores de confusión, puede atribuirse tanto al edentulismo (secuela de EP) como a niveles elevados de interleucina 6 en el suero, lo que confirmó estudios previamente realizados. Tan et al. (27) identificaron una relación entre las especies bacterianas patógenas presentes en la cavidad oral y los pulmones, lo cual apoyó la hipótesis de que la cavidad oral podría ser un reservorio para patógenos pulmonares. Otros estudios, como el de Shen et al. (28) plantearon que los pacientes con EPOC tienen un mayor riesgo de desarrollar EP que la población general, lo que podría sugerir una relación inversa de dichas patologías. Los mismos autores también sugirieron que el riesgo de EP es proporcional al control de la EPOC y que los pacientes que recibían tratamiento con corticosteroides desarrollaban EP con más frecuencia.

Kim et al. (29) encontraron que la pérdida dental se asociaba de manera significativa con la obstrucción del flujo aéreo en hombres. Sus hallazgos sugieren que el número de dientes en la boca podría ser uno de los parámetros para evaluar las enfermedades pulmonares obstructivas, incluyendo la EPOC. Complementando lo expuesto, Gómez et al. (30) observaron un vínculo consistente entre el sangrado de las encías (signo de EP) y la enfermedad obstructiva de las vías respiratorias, que si bien no se pudo explicar por factores de riesgo comunes o factores metabólicos, dio cabida para especular que los patógenos orales pueden tener un impacto desfavorable en las vías respiratorias. No obstante, la pérdida de piezas 
dentarias parcial o total, que en la mayoría de los casos deriva de una EP crónica no tratada, puede ser también secuela del hábito de fumar, tal y como lo sugirieron Henke et al. (31), quienes encontraron que, dentro de un entorno clínico real, los pacientes portadores de prótesis dentales mostraron una escasa asociación con la función pulmonar, lo que les permitió sugerir una pequeña disfunción y obstrucción de las vías aéreas. No obstante, para estos autores, la mayoría de las asociaciones se explicaron por el hábito de fumar y la edad, pues no se halló una relación causal entre la EP y la EPOC.

Muthu et al. (32) afirmaron que la colonización oral por parte de microrganismos que afectan el sistema respiratorio es un factor de riesgo para el desarrollo de enfermedades respiratorias y que las intervenciones dirigidas a reducir la carga microbiológica oral disminuyen la incidencia de estas enfermedades. Teniendo en cuenta lo anterior, se deduce que la carga bacteriana oral afecta significativamente el comportamiento de enfermedades respiratorias, de acuerdo con lo sugerido por Fernández et al. (33), quienes identificaron que la severidad de la EP se asocia directamente con los días de estancia hospitalaria de pacientes con enfermedad respiratoria.

Los estudios más recientes demostraron una relación donde la EP interviene directamente en la EPOC, como lo hallado y referido por Winning et al. (34) en un grupo homogéneo de hombres dentados, donde la periodontitis crónica se asoció de manera significativa con una función respiratoria reducida. Asimismo, Tan et al. (35) confirmaron que la destrucción de los tejidos periodontales y los patógenos orales se asocian con la función pulmonar. Harland et al. (36), en su estudio en una población de hombres japoneses, describieron una asociación significativa entre el tabaquismo y la EPOC para los sujetos con periodontitis. Encontraron que esta relación fue más débil para aquellos sin periodontitis, lo cual sugiere que la periodontitis modifica la asociación entre el tabaquismo y la EPOC.

Generalmente, los diferentes estudios descriptivos observacionales han generado hipótesis sobre el tipo de asociación entre la EP y la EPOC: sugieren que es muy estrecha y que se debe considerar una relación bidireccional donde la EP induce un aumento de las exacerbaciones y complicaciones de la EPOC, así como un aumento de la obstrucción pulmonar. La EPOC, a su vez, aumenta el riesgo de desarrollar EP por la dificultad en la higiene oral, la condición proinflamatoria y la susceptibilidad a la infección con patógenos periodontales.

\section{Estudios de cohortes retrospectivos}

Los estudios de cohortes retrospectivos han demostrado que existe relación entre ambas enfermedades y, sobre todo, una predisposición a las complicaciones de la enfermedad pulmonar en pacientes con periodontitis. Scannapieco y Ho (37) analizaron de forma transversal los datos de la Tercera Encuesta Nacional de Salud y Nutrición (la cual consiste en un estudio retrospectivo), que documentó el estado general de sujetos de los Estados Unidos entre 1988 y 1994. Esta base de datos incluyó 13.792 sujetos mayores de 20 años con al menos 6 dientes en la boca. Se registraron los sujetos con historia de bronquitis o enfisema (consideradas estas dos manifestaciones juntas como EPOC) y, además, se analizó el estado de salud oral. Se encontró que los sujetos con EPOC tenían más pérdida de inserción periodontal que los pacientes sin EPOC y se logró también determinar que los sujetos con pérdida de inserción clínica mayor o igual a $3 \mathrm{~mm}$ tenían alto riesgo de desarrollar EPOC. Ante estos resultados, los autores manifestaron que hubo una tendencia en la cual la función pulmonar parece disminuir a medida que la pérdida de inserción clínica aumenta.

Hyman y Reid (38) analizaron datos de pacientes con EPOC y concluyeron que fumar puede ser un cofactor tanto para la EP como para EPOC, ya que los pacientes fumadores presentaron variables clínicas asociadas con mayor severidad en ambas patologías.

Posteriormente, Chrysanthakopoulos y Chrysanthakopoulos (39) demostraron la asociación entre EP y varias 
enfermedades sistémicas, incluyendo enfermedades cardiovasculares, diabetes, hepatitis, enfermedades renales, enfermedades respiratorias, entre otras. Específicamente, revisando el caso de EPOC, este estudio mostró una relación positiva entre la profundidad al sondaje y la pérdida de inserción clínica con las manifestaciones respiratorias. Por su parte, el estudio de Shen et al. (40) reportó que el grupo de pacientes con EPOC que recibieron tratamiento periodontal desarrollaron menos riesgo de eventos adversos respiratorios, lo que redujo el uso de servicios de emergencia, hospitalización y admisión a la unidad de cuidado intensivo, además de reducir el índice de mortalidad. Ello demostró que la disminución de la carga microbiológica y el factor local periodontal puede ser determinante en el tratamiento y calidad de vida del paciente con enfermedades respiratorias.

En términos generales, los estudios retrospectivos incluidos en esta revisión dan cuenta de una relación estrecha entre ambas patologías, siendo determinante la severidad de la EP en la frecuencia de complicaciones de EPOC; sin embargo, no es posible determinar si esta relación es causa-efecto, por lo que aún se dificulta afirmar que la EP sea un factor de riesgo para la EPOC.

\section{Casos y controles}

Los estudios observacionales analíticos, tipo casos y controles, han demostrado que existe evidencia en la relación entre ambas enfermedades, además de lograr analizar el grado de asociación que se presenta. En esta revisión se encontraron varios estudios de este tipo, algunos con un gran número de muestra y otros con pocos pacientes considerados estudio piloto. De estos artículos, el 92,8 \% concluyó que existe esta relación; mientras que el $7,14 \%$ restante indica que no existe dicha relación.

En el estudio de Kowalski et al. (41) se mostró una correlación positiva entre la profundidad de la bolsa y el índice de placa con la severidad de la EPOC. Los autores de este estudio concluyeron que la severidad de la EP tiene una relación de causa-efecto con la EPOC. Más adelante, en un estudio similar, Wang et al. (42) también analizaron las variables clínicas periodontales y tuvieron en cuenta los hábitos y conocimientos en higiene oral de los pacientes, lo cual mostró que los pacientes con mayor pérdida de dientes y alto índice de placa reportaron poca experiencia en el cepillado y en el uso de la seda dental, así como poco conocimiento sobre el impacto que tiene la mala higiene oral en cuanto riesgo aumentado de desarrollar EPOC; incluso, al ajustar los resultados por edad, sexo, índice de masa corporal y fumar. Si et al. (43) hicieron un estudio similar con análisis de las mismas variables y hallaron una fuerte asociación incluso para fumadores y no fumadores. Para estos autores, la EP fue un predictor de EPOC en una población china.

En el estudio de Peter et al. (44) se encontró que los individuos con EPOC tenían valores significativamente más altos en la pérdida de inserción clínica, profundidad de bolsa e índice de higiene oral, y se observó una correlación positiva entre los valores del volumen espiratorio forzado en un minuto y pérdida de inserción clínica, profundidad de bolsa e índice gingival, lo que indica una tendencia de incremento en la obstrucción pulmonar a medida que aumenta la severidad de la EP (44). Scannapieco (45) había encontrado una correlación entre el nivel de inserción clínica, la profundidad de bolsa y el índice gingival con el volumen espiratorio forzado en un minuto, de tal manera que los sujetos que presentaron disminución en este marcador tenían peor estado periodontal. Por su parte, Ledić et al. (46) encontraron asociación entre las dos enfermedades con un OR de 3,2 (95\%; IC: $1,0-9,8)$; sin embargo, consideraron que la EP es un indicador de riesgo para el desarrollo de EPOC.

En contraposición con los autores mencionados, Bergström et al. (47) analizaron tres grupos de pacientes: el grupo 1, constituido por 28 sujetos fumadores con EPOC; el grupo 2, conformado por 29 sujetos fumadores sin EPOC, y el grupo 3, con 23 sujetos no fumadores y sanos. Después de analizar las variables 
clínicas tanto de periodontitis como de EPOC, los autores concluyeron que la periodontitis está fuertemente asociada con el hábito de fumar, pero débilmente asociada con el grado de destrucción del tejido pulmonar y con la limitación permanente al flujo del aire. Es importante notar que, aun cuando existe todavía controversia respecto al tipo de asociación (aunque son más los estudios que reportan asociación entre las dos patologías), no hay una constante en cuanto al tipo de asociación; por lo tanto, la evidencia todavía no sustenta claramente si la EP deba considerarse un factor de riesgo o un indicador de riesgo. Además de la relación entre ambas enfermedades, se ha podido determinar que la EP y la higiene oral pueden ser factores determinantes en la frecuencia de exacerbaciones de EPOC. En este sentido, Liu et al. (48) observaron que en aquellos pacientes con mayor pérdida de dientes, índice de placa más alto y menos tiempo de cepillado, hubo una correlación positiva con la frecuencia de las exacerbaciones de la EPOC. Kucukcoskun et al. (49) fueron un poco más allá y analizaron el impacto del tratamiento periodontal, dividiendo la muestra en dos grupos: uno con 20 sujetos a quienes se les realizó terapia periodontal y otro con 20 sujetos que no recibieron tratamiento periodontal. Los autores concluyeron que en los pacientes que recibieron terapia periodontal disminuyó la frecuencia de exacerbaciones.

Otros autores, aparte de estudiar la asociación entre ambas patologías, analizaron algunos marcadores séricos, moléculas proinflamatorias tanto en suero como en líquido gingival crevicular o niveles de vitaminas y su relación en la evolución de la enfermedad, lo cual es importante entendiendo el papel de la inflamación en la fisiopatología de ambas enfermedades y a que, en parte, esta es una de las vías a través de las cuales se pueden conectar. Zhou et al. (50) realizaron un estudio con 193 sujetos con EPOC y 181 controles a quienes además de examinar su estado periodontal y pulmonar se les midieron los niveles de 25- $(\mathrm{OH})$ vitamina $\mathrm{D}$ en suero, los cuales resultaron significativamente más bajos en el grupo de EPOC y significativamente asociados con variables clínicas periodontales, lo que pudo indicar una mayor severidad de la enfermedad incluyendo el alto índice de placa, por lo que los autores concluyeron que las concentraciones bajas de $25-(\mathrm{OH})$ vitamina $\mathrm{D}$ en suero fueron significativamente asociadas a peor salud periodontal y a un incremento del riesgo para desarrollar EPOC. La 25-(OH) vitamina D controla genes involucrados con la regulación de la proliferación celular, vías antinflamatorias, control de la apoptosis, inmunomodulación de la respuesta inmune adaptativa y estímulo de la respuesta inmune innata, lo que puede explicar dichos resultados.

Por su parte, Yildirim et al. (51) midieron los niveles de metaloproteinasas de matriz (MMP-8 y MMP-13) y del inhibidor de metaloproteinasas-1 (TIMP-1) en suero y saliva de 36 pacientes con EPOC y 20 pacientes del grupo control. Los autores reportaron, mediante inmunoensayos, un aumento de MMP-8 en suero en el grupo de pacientes con EPOC, aunque mediante ELISA no hubo diferencias entre los grupos en la detección de los diferentes marcadores mencionados. El aumento de MMP-8 puede estar relacionado con los marcadores inflamatorios propios de la enfermedad, pero estos marcadores bioquímicos no proveen soporte para correlacionar la EP y EPOC. En el estudio de Öztekin et al. (52) se incluyeron 52 pacientes con EPOC y 38 pacientes sanos en quienes se analizaron variables clínicas periodontales y se tomaron muestras de líquido gingival crevicular para determinar los niveles de proteína C reactiva de alta sensibilidad (hs-PCR), IL-1 $\beta$ y prostaglandina E2, y de suero para determinar los niveles de proteína $\mathrm{C}$ reactiva de alta sensibilidad (hs-PCR). Los resultados del estudio mostraron valores más altos en los niveles de hs-PCR en suero y fluido gingival crevicular, IL-1 $\beta$ y PGE2 y en los índices de placa y gingival, además de mayor pérdida dental en el grupo de EPOC comparado con el control.

Si bien los estudios han mostrado que la EP y la higiene oral son elementos importantes en la progresión y exacerbaciones de la EPOC, analizar el impacto del tratamiento periodontal puede brindar una mejor orientación más sobre 
el tipo se asociación. Así es como Agado et al. (53) reclutaron a 30 voluntarios con EPOC y los clasificaron en tres grupos. Un grupo de 10 participantes a los que se les realizó detartraje con ultrasonido y magnetoterapia, un segundo grupo de 10 participantes a quienes se les realizó detartraje manual y un tercer grupo de 10 participantes al que no se les realizó terapia periodontal. El estudio pudo demostrar que el tratamiento periodontal no generó efectos en la calidad de vida de los pacientes con EPOC, aunque tampoco se relacionó con efectos adversos. En contraste con estos resultados, Zhou $\mathrm{X}$ et al. (54) realizaron un estudio en 60 pacientes con EPOC divididos en tres grupos; al primer grupo se le realizó detartraje y alisado radicular; al segundo grupo, detartraje supragingival, y al tercero se le dio instrucciones de higiene oral. A los tres grupos se les evaluó la línea de base y estados a los seis meses, al año y a los dos años. Los resultados mostraron que en los dos grupos de terapia hubo una reducción en la frecuencia de exacerbaciones de EPOC comparado con el grupo control. Finalmente, Pranav et al. (55) concluyeron que, luego de estudiar a 198 pacientes divididos en 2 grupos, 99 de ellos con enfermedades respiratorias y 99 pacientes sanos, existe una fuerte asociación entre periodontitis y EPOC.

\section{Metanálisis}

El único metanálisis incluido en esta revisión fue el de Zeng et al. (56), en el cual incluyeron 14 estudios publicados hasta el 2012, de los cuales uno era de casos y controles anidado, ocho de casos y controles y cinco observacionales. Se encontró una asociación significativa entre la EP y la EPOC $(\mathrm{OR}=2,08$; IC: $95 \%=1,48-2,91$; $p<0.001$ ), con un análisis de sensibilidad que mostró que el resultado fue sólido, y concluyendo que de acuerdo con la evidencia, la EP puede considerarse un factor de riesgo significativo e independiente para EPOC, pero que no es posible establecer si se trata de una relación causa-efecto.

\section{Conclusiones}

El $94 \%$ de las publicaciones revisadas muestra relación entre EP y EPOC, aunque no hubo consenso entre estos estudios, ya que algunos autores consideran que la relación es causaefecto, pero otros autores sugieren que la EP es un indicador de riesgo para EPOC. Sin embargo, los estudios que analizaron la higiene oral y el tratamiento periodontal refieren que mejorar los hábitos, tratar la enfermedad y reducir el factor local incide significativamente en la disminución del riesgo de desarrollar EPOC y en su gravedad, así como en reducir la frecuencia de las exacerbaciones. Los estudios muestran, además, que existen factores de riesgo compartidos para ambas patologías, como fumar y las deficiencias en la higiene oral, que son muy importantes al evaluar la predisposición de ciertos pacientes a estas patologías. Teniendo en cuenta la importancia de la higiene oral, la experiencia de cepillado y el desarrollo de la biopelícula periodontal, se infiere que las bacterias que pueden colonizar la cavidad oral, sus mecanismos de patogenicidad y su capacidad de migrar a otros tejidos diferentes al tejido periodontal son las vías a través de las cuales se conectan ambas patologías, lo que demuestra la posibilidad de que la relación sea de doble vía, en la cual el paciente con EP tiene mayor predisposición a presentar EPOC o exacerbaciones y complicaciones, y en la que el paciente con EPOC, por la dificultad en su higiene oral, tendrá una mayor predisposición a desarrollar EP, que en este tipo de pacientes tenderá a presentarse de forma moderada a severa.

La discusión resalta la importancia de establecer protocolos de tratamiento integral al paciente con EPOC, de formular campañas de prevención en salud oral dirigidas a pacientes con enfermedades respiratorias o con tendencia a desarrollarlas, de modificar las guías de atención con enfoque biopsicosocial y de desarrollar políticas de salud pública que conlleven al control de EP y EPOC. Para esto, es importante generar evidencia a partir de la investigación sobre el comportamiento y la manera como se asocian 
estas patologías en la población colombiana, dado que, de acuerdo con esta revisión de la literatura, la procedencia de los artículos seleccionados correspondió mayoritariamente a China y a Estados Unidos y no se encontraron artículos procedentes de países latinoamericanos (incluido Colombia). Por tal razón, se sugiere que se llevan a cabo estudios multidisciplinarios que generen mayor evidencia, como es el caso de ensayos clínicos controlados, para permitir analizar, explicar y comprender mejor las bases biológicas de este enlace etiopatogénico y su respectivo vínculo epidemiológico.

Conflictos de interés: los autores declaran que no existen conflictos de interés.

\section{Referencias}

1. Parashar P, Parashar A, Saraswat N, Pani P, Pani N, Joshi S. Relationship between respiratory and periodontal health in adults: a case-control study. J Int Soc Prev Community Dent. 2018;8(6):560-4.

2. Moreno S, Contreras A. Mecanismos moleculares implicados en la destrucción ósea en la periodontitis: revisión de la literatura. Clin Rev Clin Periodoncia Implantol Rehabil Oral. 2013;6(3):142-7.

3. Moreno S, Contreras A. Factores de virulencia de Porphyromonas gingivalis. Rev Funda Carraro. 2013;37:16-27.

4. Shewale A, Gattani R, Bhatia N, Mahajan R, Saravanan S. Prevalence of periodontal disease in the general population of India: a systematic review. J Clin Diagn Res. 2016;10(6):ZE04-9.

5. Lindhe J, Karring T, Lang $\mathrm{N}$. Periodontología clínica e implantología odontológica. Buenos Aires: Editorial Médica Panamericana; 2009.

6. Tejada P, Munayco A, Cortez M. Periodontal disease as a risk factor to chronic obstructive pulmonary diseases (COPD). Kiru. 2005;2(2):66-73.

7. Moreno S, Jaramillo A, Parra B, Botero J, Contreras A. Porphyromonas gingivalis Fim-A genotype distribution among Colombians. Colomb Med. 2015;46(3):122-27.

8. Takahashi T, Muro S, Tanabe S, Terada K, Kiyokawa H, Sato $S$, et al. Relationship between periodontitis-related antibody and frequent exacerbations in chronic obstructive pulmonary disease. PLoS One. 2012;7 (7):e40570.

9. Madalli R, Kheur S, Reddy M, Kheur M, Mahalle A. Assessment of role of Porphyromonas gingivalis as an aggravating factor for chronic obstructive pulmonary disease patients with periodontitis. Dent Hypotheses. 2016;7(3):100-6.

10. Liberati A, Altman D, Tetzlaff J, Mulrow C, Gøtzsche PC, Loannidis $\mathrm{J}$, et al. The PRISMA statement for reporting systematic reviews and meta-analyses of studies that evaluate health care interventions: explanation and elaboration. PLoS Med. 2009;6(7):e1000100.

11. Felton D. Complete edentulism and comorbid diseases: an update. J Prosthodont. 2016;25(1):5-20.

12. Olsen I. From the acta prize lecture 2014: the periodontal-systemic connection seen from a microbiological standpoint. Acta Odontol Scand. 2014;73(8):563-8.

13. Devlin J. Patients with chronic obstructive pulmonary disease: Management considerations for the dental team. Br Dent J. 2014; 217(5):235-7.

14. Bansal M, Khatri M, Taneja V. Potential role of periodontal infection in respiratory diseases: a review. J Med Life. 2013;6(3):244-8. 
15. Azarpazhooh A, Leake J. Systematic review of the association between respiratory diseases and oral health. J Periodontol. 2006;77(9):1465-82.

16. Garcia R, Nunn ME, Vokonas PS. Epidemiologic associations between periodontal disease and chronic obstructive pulmonary disease. Ann Periodontol. 2001;6(1):71-7.

17. Hayes C, Sparrow D, Cohen M, Vokonas P, Garcia R. The association between alveolar bone loss and pulmonary function: The VA Dental Longitudinal Study. Ann Periodontol. 1998;3(1):257-61.

18. Katancik J, Krichevsky S, Weyant R, Corby P, Bretz W, Crapo R et al. Periodontitis and airway obstruction. J Periodontol. 2005;76(11 Suppl):2161-7.

19. Leuckfeld I, Obregon-Whittle M, Lund M, Geiran O, Bjørtuft $\varnothing$, Olsen I. Severe chronic obstructive pulmonary disease: association with marginal bone loss in periodontitis. Respir Med. 2008;102 (4):488-94.

20. Deo V, Bhongade ML, Ansari S, Chavan R. Periodontitis as a potential risk factor for chronic obstructive pulmonary disease: A retrospective study. Indian J Dent Res. 2009;20(4):466-70.

21. Sharma $N$, Shamsuddin $H$. Association between respiratory disease in hospitalized patients and periodontal disease: a crosssectional study. J Periodontol. 2011;82(8):1155-60.

22. Zhou X, Wang Z, Song Y, Zhang J, Wang C. Periodontal health and quality of life in patients with chronic obstructive pulmonary disease. Respir Med. 2011;105(1):67-73.

23. Vadiraj S, Nayak R, Choudhary G, Kudyar N, Spoorthi B. Periodontal pathogens and respiratory diseasesevaluating their potential association: a clinical and microbiological study. J Contemp Dent Pract. 2013;14(4):610-5.

24. Leuckfeld I, Paster BJ, Kristoffersen A, Olsen I. Diversity of Veillonella spp. from subgingival plaque by polyphasic approach. APMIS. 2010;118(3):230-42.

25. Takahashi T, Muro S, Tanabe N, Terada K, Kiyokawa H, Sato $\mathrm{S}$ et al. Relationship between antibodies related to periodontitis and frequent exacerbations in chronic obstructive pulmonary disease. PLoS One.2012;7(7):e40570.

26. Barros S, Suruki R, Loewy Z, Beck J, Offenbacher S. A cohort study of the impact of tooth loss and periodontal disease on respiratory events among COPD subjects: modulatory role of systemic biomarkers of inflammation. PLoS One. 2013;8(8):e68592.

27. Tan L, Wang $\mathrm{H}$, Li C, Pan Y. 16S rDNA-based metagenomic analysis of dental plaque and lung bacteria in patients with severe acute exacerbations of chronic obstructive pulmonary disease. J Periodont Res. 2014;49(6):760-9.

28. Shen T, Chang P, Lin C, Chen $\mathrm{C}, \mathrm{Tu} \mathrm{C}, \mathrm{Hsia} \mathrm{T}$ et al. Risk of periodontal diseases in patients with chronic obstructive pulmonary disease: a nationwide population-based cohort study. Medicine (Baltimore). 2015;94(46):e2047.

29. Kim S, Han K, Kim S, Park C, Rhee $\mathrm{C}$, Yoon $\mathrm{H}$. The relationship between the number of natural teeth and airflow obstruction: a cross-sectional study using data from the Korean National Health and Nutrition Examination Survey. Int J Chron Obstruct Pulmon Dis. 2016;11(1):13-21. 
30. Gómez F, Pérez L, Franklin $\mathrm{K}$, Lindberg E, Bertelsen R, Benediktsdóttir B et al. The association of gum bleeding with respiratory health in a population based study from northern Europe. PLoS One. 2016;11(1):e0147518.

31. Henke C, Budweiser S, Jörres R. Lung function and associations with multiple dimensions of dental health: a prospective observational cross-sectional study. BMC Res Notes. 2016;9(1):274.

32. Muthu J, Muthanandam S, Mahendra J. Mouth the mirror of lungs: Where does the connection lie? Front. Med. 2016;10(4):405-9.

33. Fernández R, Olmedo D, Martínez D, González H, Casa G, García C. Días de estancia hospitalaria (DEH) en pacientes con enfermedades respiratorias (ER) y enfermedad periodontal (EP). Gac Med Mex. 2017;153(1):31-5.

34. Winning L, Patterson C., Cullen K, Kee F, Linden G. Chronic periodontitis and reduced respiratory function. J Clin Periodontol. 2018;46(3):266-75.

35. Tan L, Tang X, Pan C, Wang $\mathrm{H}$, Pan Y. Relationship among clinical periodontal, microbiologic parameters and lung function in participants with chronic obstructive pulmonary disease. J Periodontol. 2018;90(2):134-40.

36. Harland J, Furuta M, Takeuchi K, Tanaka S, Yamashita, Y. Periodontitis modifies the association between smoking and chronic obstructive pulmonary disease in Japanese men. J Oral Sci. 2018;60(2):226-31.

37. Scannapieco F, Ho A. Potential associations between chronic respiratory disease and periodontal disease: Analysis of National Health and Nutrition Examination Survey III. J Periodontol. 2001;72(1):50-6.
38. Hyman J, Reid B. Cigarette smoking, periodontal disease and chronic obstructive pulmonary disease. J Periodontol. 2004;75(1):9-15.

39. Chrysanthakopoulos N, Chrysanthakopoulos P. Association between indices of clinically-defined periodontitis and self-reported history of systemic medical conditions. J Invest Clin Dent. 2016;7(1):27-36.

40. Shen $T$, Chang $P$, Lin C, Chen C, Tu C, Hsia $\mathrm{T}$ et al. Periodontal treatment reduces risk of adverse respiratory events in patients with chronic obstructive pulmonary disease: A propensitymatched cohort study. Medicine (Baltimore). 2016;95(20):e3735.

41. Kowalski M, Kowalska E, Split M, Split W, Wierzbicka F, Pawlicki L et al. Assessment of periodontal state in patients with chronic obstructive pulmonary disease - Part II. Pol Merkur Lekarski. 2005;19(112):537-41.

42. Wang Z, Zhou X, Zhang J, Zhang L, Song Y, Hu FB et al. Periodontal health, oral health behaviours, and chronic obstructive pulmonary disease. J Clin Periodontol. 2009; 36(9):750-5.

43. Si Y, Fan H, Song Y, Zhou $X$, Zhang J, Wang Z. Association between periodontitis and chronic obstructive pulmonary disease in a Chinese population. J Periodontol. 2012;83(10):1288-96.

44. Peter K, Mute B, Doiphode S, Bardapurkar S, Borkar M, Raje D. Association between periodontal disease and chronic obstructive pulmonary disease: a reality or just a dogma? J Periodontol. 2013;84(12):1717-23.

45. Scannapieco F. Individuals with chronic obstructive pulmonary disease (COPD) may be more likely to have more severe periodontal disease than 
individuals without COPD. J Evid Based Dent Pract. 2014;14(2):79-81.

46. Ledic K, Marinkovic S, Puhar I, Spalj S, Popovic G, Ivic K et al. Periodontal disease increases risk for chronic obstructive pulmonary disease. Coll Antropol. 2013;37(3):937-42.

47. Bergström J, Cederlund K, Dahlén B, Lantz AS, Skedinger M, Palmberg $\mathrm{L}$ et al. Dental health in smokers with and without COPD. PLoS One. 2013;8(3):e59492.

48. Liu Z, Zhang W, Zhang J, Zhou X, Zhang L, Song Y et al. Oral hygiene, periodontal health and chronic obstructive pulmonary disease exacerbations. J Clin Periodontol. 2012;39(1):45-52.

49. Kucukcoskun M, Baser U, Oztekin G, Kiyan E, Yalcin F. Initial periodontal treatment for prevention of chronic obstructive pulmonary disease exacerbations. J Periodontol. 2013;84(7):863-70.

50. Zhou X, Han J, Song Y, Zhang J, Wang Z. Serum levels of 25hydroxyvitamin $\mathrm{D}$, oral health and chronic obstructive pulmonary disease. J Clin Periodontol. 2012;39(4):350-6.

51. Yıldırım E, Kormi I, Başoğlu Ö, Gurgun A, Kaval B, Sorsa T et al. Periodontal health and serum, saliva matrix metalloproteinases in patients with mild chronic obstructive pulmonary disease. J Periodontal Res. 2013;48(3):269-75.

52. Oztekin G, Baser U, Kucukcoskun M, Tanrikulu S, Ademoglu E, Isik $G$ et al. The association between periodontal disease and chronic obstructive pulmonary disease: a case control study. COPD. 2014;11(4):424-30.

53. Agado B, Crawford B, DeLaRosa J, Bowen D, Peterson T, Neill K et al. Effects of periodontal instrumentation on quality of life and illness in patients with chronic obstructive pulmonary disease: a pilot study. J Dent Hyg. 2012; 86(3):204-14.

54. Zhou X, Han J, Liu Z, Song Y, Wang Z, Sun Z. Effects of periodontal treatment on lung function and exacerbation frequency in patients with chronic obstructive pulmonary disease and chronic periodontitis: a 2-year pilot randomized controlled trial. J Clin Periodontol. 2014;41(6):564-72.

55. Parashar P, Parashar A, Saraswat N, Pani P, Pani N, Joshi S. Relationship between respiratory and periodontal health in adults: a case-control study. J Int Soc Prev Community Dent. 2019;8(6):560-4.

56. Zeng $\mathrm{X}$, Tu M, Liu D, Zheng D, Zhang J, Leng W. Periodontal disease and risk of chronic obstructive pulmonary disease: a meta-analysis of observational studies. PLoS One. 2012; 7 (10):e46508.

57. Usher A, Stockley R. The link between chronic periodontitis and COPD: a common role for the neutrophil? BMC Medicine. 2013;11(1):241-52.

58. Linden G, Herzberg M; Working group 4 of joint EFP/AAP Workshop. Periodontitis and systemic diseases: a record of discussions of working group 4 of the Joint EFP/AAP Workshop on Periodontitis and Systemic Diseases. J Clin Periodontol. 2013;40(14):S20-3.

59. Martos R, Márton I. Possible correlations between periodontitis and chronic obstructive pulmonary disease: review of the literature. Fogorv Sz. 2011;104(3):87-92 


\section{Anexo 1.}

\section{Artículos obtenidos mediante la búsqueda sistemática en Medline a través de la metodología PRISMA (10)}

\begin{tabular}{|c|c|c|c|c|c|c|c|}
\hline Autores & Año & Pais & $\begin{array}{l}\text { Tipo de } \\
\text { estudio }\end{array}$ & Objetivo & Muestra total & Conclusión & $\begin{array}{l}\text { Relación } \\
\text { entre EP y } \\
\text { EPOC }\end{array}$ \\
\hline Winning et al. (34) & 2018 & $\begin{array}{l}\text { Irlanda } \\
\text { del Norte }\end{array}$ & Descriptivo & $\begin{array}{l}\text { Investigar si hubo una } \\
\text { asociación entre la } \\
\text { periodontitis crónica y la } \\
\text { reducción de la función } \\
\text { respiratoria }\end{array}$ & 1380 pacientes & $\begin{array}{l}\text { La periodontitis crónica se } \\
\text { asoció significativamente } \\
\text { con una función respiratoria } \\
\text { reducida }\end{array}$ & $\mathrm{Si}$ \\
\hline Tan et al. (35) & 2018 & China & Descriptivo & $\begin{array}{l}\text { Evaluar la relación entre } \\
\text { clínica periodontal, } \\
\text { parámetros } \\
\text { microbiológicos y } \\
\text { función pulmonar en } \\
\text { pacientes con EPOC }\end{array}$ & $\begin{array}{l}160 \text { pacientes: } \\
80 \text { pacientes con } \\
\text { EPOC (grupo } \\
\text { intervención) y } \\
80 \text { pacientes sin } \\
\text { EPOC (grupo de } \\
\text { control) } \\
\end{array}$ & $\begin{array}{l}\text { La destrucción periodontal } \\
\text { y los patógenos orales se } \\
\text { asocian con la función } \\
\text { pulmonar }\end{array}$ & $\mathrm{Si}$ \\
\hline Harland et al. (36) & 2018 & Japón & Descriptivo & $\begin{array}{l}\text { Examinar la asociación } \\
\text { entre periodontitis, } \\
\text { tabaquismo y EPOC }\end{array}$ & 1474 pacientes & $\begin{array}{l}\text { La asociación entre } \\
\text { tabaquismo y EPOC fue } \\
\text { significativa. La } \\
\text { periodontitis modifica la } \\
\text { asociación entre } \\
\text { tabaquismo y EPOC }\end{array}$ & Si \\
\hline Parashar et al. (55) & 2018 & India & $\begin{array}{l}\text { Estudio de } \\
\text { casos y } \\
\text { controles }\end{array}$ & $\begin{array}{l}\text { Investigar la relación } \\
\text { entre la salud periodontal } \\
\text { y las enfermedades } \\
\text { respiratorias }\end{array}$ & $\begin{array}{l}198 \text { pacientes: } \\
99 \text { pacientes con } \\
\text { enfermedades } \\
\text { respiratorias } \\
\text { (grupo } \\
\text { intervención)y } \\
99 \text { pacientes con } \\
\text { función } \\
\text { pulmonar } \\
\text { normal en } \\
\text { (grupo control) }\end{array}$ & $\begin{array}{l}\text { Se encontró una fuerte } \\
\text { asociación entre } \\
\text { periodontitis y EPOC }\end{array}$ & $\mathrm{Si}$ \\
\hline $\begin{array}{l}\text { Fernández et al. } \\
\text { (33) }\end{array}$ & 2017 & México & Descriptivo & $\begin{array}{l}\text { Establecer la asociación } \\
\text { entre la enfermedad } \\
\text { periodontal y las } \\
\text { enfermedades } \\
\text { respiratorias en relación } \\
\text { con los dias de estancia } \\
\text { hospitalaria }\end{array}$ & 3059 pacientes & $\begin{array}{l}\text { La gravedad de la } \\
\text { enfermedad periodontal se } \\
\text { asocia directamente con los } \\
\text { dias de estancia hospitalaria } \\
\text { en pacientes con } \\
\text { enfermedades respiratorias }\end{array}$ & $\mathrm{Si}$ \\
\hline
\end{tabular}


Anexo 1 (cont.)

\begin{tabular}{|c|c|c|c|c|c|c|c|}
\hline Muthu et al. (32) & 2016 & 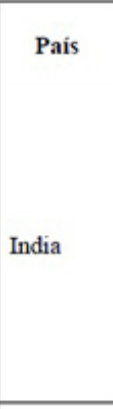 & $\begin{array}{r}\begin{array}{l}\text { Tipo de } \\
\text { estudio }\end{array} \\
\text { Descriptivo }\end{array}$ & $\begin{array}{l}\quad \text { Objetivo } \\
\\
\text { Indicar la asociación } \\
\text { entre la enfermedad } \\
\text { periodontal y las } \\
\text { enfermedades } \\
\text { respiratorias }\end{array}$ & $x^{2}$ & $\begin{array}{l}\quad \text { Conclusión } \\
\text { La colonización oral por } \\
\text { patógenos respiratorios } \\
\text { parece ser un factor de } \\
\text { riesgo para el desarrollo de } \\
\text { enfermedades respiratorias. } \\
\text { Las intervenciones } \\
\text { dirigidas a reducir el conteo } \\
\text { bacteriano oral dieron lugar } \\
\text { a una reducción de la } \\
\text { incidencia de estas } \\
\text { enfermedades }\end{array}$ & $\begin{array}{l}\text { Relación } \\
\text { entre EP y } \\
\text { EPOC }\end{array}$ \\
\hline Shen et al. (40) & 2016 & China & $\begin{array}{l}\text { Cohorte } \\
\text { retrospectiv } \\
0\end{array}$ & \begin{tabular}{|l} 
Investigar si el \\
tratamiento periodontal \\
para pacientes con EPOC \\
puede reducir el riesgo \\
de eventos respiratorios \\
adversos incluyendo \\
exacerbación aguda, \\
neumonia e insuficiencia \\
respiratoria aguda \\
\end{tabular} & 5.562 pacientes & $\begin{array}{l}\text { El tratamiento periodontal } \\
\text { para los pacientes con } \\
\text { EPOC puede reducir el } \\
\text { riesgo de eventos } \\
\text { respiratorios adversos y la } \\
\text { mortalidad. La atención } \\
\text { periodontal adecuada es } \\
\text { importante para los } \\
\text { pacientes con EPOC y con } \\
\text { enfermedad periodontal }\end{array}$ & $\mathrm{Si}$ \\
\hline Henke et al. (31) & 2016 & $\begin{array}{l}\text { Alemani } \\
\text { a }\end{array}$ & Descriptivo & $\begin{array}{l}\text { Evaluar las asociaciones } \\
\text { entre salud dental y } \\
\text { medidas espirométricas } \\
\text { en una población general }\end{array}$ & 206 pacientes & $\begin{array}{l}\text { La presencia de prótesis } \\
\text { dentales mostró una débil } \\
\text { asociación con la función } \\
\text { pulmonar, lo que sugiere } \\
\text { una pequeña disfunción de } \\
\text { las vias aéreas y } \\
\text { obstrucción. La mayoria de } \\
\text { las asociaciones se explicó } \\
\text { por los hábitos de fumar y } \\
\text { la edad }\end{array}$ & No \\
\hline Gómez et al. (30) & 2016 & $\begin{array}{l}\text { Paises } \\
\text { del norte } \\
\text { de } \\
\text { Europa }\end{array}$ & Descriptivo & $\begin{array}{l}\text { Investigar si el sangrado } \\
\text { de las encias está } \\
\text { relacionado con el asma, } \\
\text { sintomas respiratorios y } \\
\text { EPOC autodeclarada }\end{array}$ & 13.409 pacientes & $\begin{array}{l}\text { Se observó un vínculo } \\
\text { consistente entre el } \\
\text { sangrado de las encias y la } \\
\text { enfermedad obstructiva de } \\
\text { las vias respiratorias, no } \\
\text { explicado por factores de } \\
\text { riesgo comunes o factores } \\
\text { metabólicos. Se especula } \\
\text { que los patógenos orales } \\
\text { pueden tener un impacto } \\
\text { desfavorable en las vias } \\
\text { respiratorias } \\
\end{array}$ & $\mathrm{Si}$ \\
\hline Kim et al. (29) & 2015 & Corea & Descriptivo & $\begin{array}{l}\text { Examinar la relación } \\
\text { entre el número de } \\
\text { dientes y la obstrucción } \\
\text { del flujo aéreo } \\
\text { (caracteristica central de } \\
\text { la EPOC) } \\
\end{array}$ & 3089 pacientes & $\begin{array}{l}\text { La pérdida de dientes } \\
\text { naturales se asoció } \\
\text { significativamente con la } \\
\text { presencia de obstrucción } \\
\text { del flujo aéreo }\end{array}$ & Si \\
\hline Shen et al. (28) & 2015 & China & Descriptivo & $\begin{array}{l}\text { Utilizar los datos de la } \\
\text { base de datos NHI para } \\
\text { determinar si los } \\
\text { pacientes con EPOC } \\
\text { tienen un mayor riesgo } \\
\text { de desarrollar } \\
\text { enfermedad periodontal }\end{array}$ & 22.332 pacientes & $\begin{array}{l}\text { Los pacientes con EPOC } \\
\text { tienen un mayor riesgo de } \\
\text { desarrollar EP que la } \\
\text { población general. El riesgo } \\
\text { de enfermedad periodontal } \\
\text { es proporcional al control } \\
\text { de la EPOC. Los pacientes } \\
\text { que reciben tratamiento con } \\
\text { corticosteroides tienen un } \\
\text { mayor riesgo de desarrollar } \\
\text { enfermedad periodontal }\end{array}$ & Si \\
\hline Felton (11) & 2015 & $\begin{array}{l}\text { Estados } \\
\text { Unidos }\end{array}$ & Revisión & $\begin{array}{l}\text { Proporcionar una } \\
\text { actualización de los } \\
\text { articulos publicados } \\
\text { desde } 2008 \text { sobre la } \\
\text { relación entre el } \\
\text { edentulismo y diferentes } \\
\text { enfermedades sistémicas } \\
\text { (incluida EPOC) } \\
\end{array}$ & No aplica & $\begin{array}{l}\text { La pérdida de dientes y el } \\
\text { edentulismo completo se } \\
\text { asocian con EPOC }\end{array}$ & $\mathrm{Si}$ \\
\hline
\end{tabular}


Anexo 1 (cont.)

\begin{tabular}{|c|c|c|c|c|c|c|c|}
\hline Autores & Año & Pais & $\begin{array}{l}\text { Tipo de } \\
\text { estudio }\end{array}$ & Objetivo & Muestra total & Conclusión & $\begin{array}{l}\text { Relación } \\
\text { entre EP y } \\
\text { EPOC }\end{array}$ \\
\hline Olsen (12) & 2014 & Croacia & Revisión & $\begin{array}{l}\text { Dar una visión general de } \\
\text { la conexión periodontal } \\
\text { sistemica vista desde la } \\
\text { perspectiva de la } \\
\text { microbiologia }\end{array}$ & No aplica & $\begin{array}{l}\text { Las bacterias periodontales } \\
\text { pueden participar en } \\
\text { infecciones extraorales } \\
\text { tales como enfermedad } \\
\text { cardiovascular, diabetes, } \\
\text { adenomatosis pulmonar } \\
\text { ovina, preeclampsia, } \\
\text { EPOC, neumonia, artritis } \\
\text { reumatoide, insuficiencia } \\
\text { renal crónica, obesidad, } \\
\text { cáncer, MetS y deterioro } \\
\text { cognitivo. La mayoria de } \\
\text { los conocimientos se basa } \\
\text { en asociaciones que no } \\
\text { implican necesariamente } \\
\text { causalidad }\end{array}$ & $\mathrm{Si}$ \\
\hline Devlin (13) & 2014 & $\begin{array}{l}\text { Reino } \\
\text { Unido }\end{array}$ & Revisión & $\begin{array}{l}\text { Describir las } \\
\text { implicaciones orales y } \\
\text { dentales de EPOC }\end{array}$ & No aplica & $\begin{array}{l}\text { EPOC hace que los } \\
\text { pacientes sufran de disnea y } \\
\text { esto puede comprometer } \\
\text { cualquier cuidado dental de } \\
\text { rutina (hábitos de higiene } \\
\text { oral) }\end{array}$ & Sí \\
\hline $\begin{array}{l}\text { Chrysanthakopoul } \\
\text { os et al. (39) }\end{array}$ & 2014 & Grecia & $\begin{array}{l}\text { Estudio } \\
\text { retrospectiv } \\
0\end{array}$ & $\begin{array}{l}\text { Investigar si existen } \\
\text { posibles asociaciones } \\
\text { entre indices de } \\
\text { periodontitis y varias } \\
\text { condiciones médicas } \\
\text { sistémicas en pacientes } \\
\text { ambulatorios remitidos a } \\
\text { una clinica hospitalaria }\end{array}$ & 3360 pacientes & $\begin{array}{l}\text { Los hallazgos confirman } \\
\text { los resultados de } \\
\text { investigaciones previas en } \\
\text { las que una serie de } \\
\text { condiciones médicas } \\
\text { sistémicas (incluida EPOC) } \\
\text { se asociaron } \\
\text { significativamente con la } \\
\text { profundidad de bolsa de } \\
\text { sondeo o pérdida de } \\
\text { inserción clínica } \\
\end{array}$ & Si \\
\hline Scannapieco (45) & 2014 & $\begin{array}{l}\text { Estados } \\
\text { Unidos }\end{array}$ & $\begin{array}{l}\text { Casos y } \\
\text { controles }\end{array}$ & $\begin{array}{l}\text { Determinar la asociación } \\
\text { entre enfermedad } \\
\text { periodontal y EPOC }\end{array}$ & 501 pacientes & $\begin{array}{l}\text { Aunque el presente estudio } \\
\text { no puede determinar la } \\
\text { asociación causal, } \\
\text { proporciona pruebas } \\
\text { sustanciales de que la mala } \\
\text { salud periodontal se asocia } \\
\text { con EPOC }\end{array}$ & Si \\
\hline Zhou et al. (54) & 2014 & China & $\begin{array}{l}\text { Casos y } \\
\text { controles }\end{array}$ & $\begin{array}{l}\text { Evaluar los efectos } \\
\text { directos de la terapia } \\
\text { periodontal en pacientes } \\
\text { con EPOC con } \\
\text { periodontitis crónica }\end{array}$ & 60 pacientes & $\begin{array}{l}\text { Se sugiere que la terapia } \\
\text { periodontal en pacientes } \\
\text { con EPOC con periodontitis } \\
\text { crónica puede mejorar la } \\
\text { función pulmonar y } \\
\text { disminuir la frecuencia de } \\
\text { exacerbación de la EPOC } \\
\end{array}$ & $\mathrm{Si}$ \\
\hline Tan et al. (27) & 2014 & China & Descriptivo & $\begin{array}{l}\text { Determinar si la } \\
\text { biopelícula oral puede } \\
\text { albergar bacterias } \\
\text { patógenas que } \\
\text { eventualmente pueden } \\
\text { causar infecciones } \\
\text { pulmonares en pacientes } \\
\text { con exacerbación aguda } \\
\text { de la EPOC }\end{array}$ & 53 pacientes & $\begin{array}{l}\text { Se ha identificado una } \\
\text { relación entre especies } \\
\text { bacterianas patógenas } \\
\text { presentes en la cavidad oral } \\
\text { y los pulmones, apoyando } \\
\text { la hipótesis que la cavidad } \\
\text { oral puede ser un reservorio } \\
\text { para patógenos pulmonares }\end{array}$ & Si \\
\hline Oztekin et al. (52) & 2014 & Turquía & $\begin{array}{l}\text { Casos y } \\
\text { controles }\end{array}$ & $\begin{array}{l}\text { Evaluar los efectos de } \\
\text { EPOC en los tejidos } \\
\text { periodontales }\end{array}$ & 52 pacientes & $\begin{array}{l}\text { EPOC puede estar asociada } \\
\text { con enfermedad periodontal } \\
\text { a partir de un menor } \\
\text { número de dientes y } \\
\text { mayores niveles de } \\
\text { mediadores inflamatorios, } \\
\text { lo cual puede ser un reflejo } \\
\text { de los efectos sistémicos de } \\
\text { EPOC en los tejidos } \\
\text { periodontales }\end{array}$ & Si \\
\hline
\end{tabular}


Anexo 1 (cont.)

\begin{tabular}{|c|c|c|c|c|c|c|c|}
\hline Autores & Año & Pais & $\begin{array}{l}\text { Tipo de } \\
\text { estudio }\end{array}$ & Objetivo & Muestra total & Conclusión & $\begin{array}{c}\text { Relación } \\
\text { entre EP y } \\
\text { EPOC }\end{array}$ \\
\hline Vadiraj et al. (23) & 2013 & India & Descriptivo & $\begin{array}{l}\text { Evaluar si existe alguna } \\
\text { asociación entre } \\
\text { enfermedades } \\
\text { respiratorias y estado de } \\
\text { salud periodontal clínica } \\
\text { o microbiológicamente }\end{array}$ & 100 pacientes & $\begin{array}{l}\text { El riesgo de EPOC parecia } \\
\text { estar significativamente } \\
\text { elevado cuando la pérdida } \\
\text { de inserción se encontró } \\
\text { que era severa }\end{array}$ & Si \\
\hline Ledic et al. (46) & 2013 & Croacia & $\begin{array}{l}\text { Cohorte } \\
\text { retrospectiv } \\
0\end{array}$ & $\begin{array}{l}\text { Explorar si la } \\
\text { enfermedad periodontal } \\
\text { puede ser un indicador de } \\
\text { riesgo para EPOC }\end{array}$ & 136 pacientes & $\begin{array}{l}\text { Se sugiere que la } \\
\text { enfermedad periodontal } \\
\text { puede ser un indicador de } \\
\text { riesgo para EPOC }\end{array}$ & $\mathrm{Si}$ \\
\hline Usher et al. (57) & 2013 & $\begin{array}{l}\text { Inglaterr } \\
\text { a }\end{array}$ & Revisión & $\begin{array}{l}\text { Revisar la evidencia } \\
\text { epidemiológica y } \\
\text { fisiopatológica } \\
\text { disponible hasta la fecha } \\
\text { y determinar si existe una } \\
\text { base para una asociación } \\
\text { entre la EPOC y la } \\
\text { periodontitis y, de ser asi, } \\
\text { las implicaciones para } \\
\text { una mayor investigación } \\
\text { y tratamiento }\end{array}$ & No aplica & $\begin{array}{l}\text { Aunque la evidencia de una } \\
\text { asociación independiente } \\
\text { entre periodontitis crónica y } \\
\text { EPOC se hace más fuerte, } \\
\text { siguen faltando estudios } \\
\text { definitivos diseñados para } \\
\text { establecer causas y efectos } \\
\text { del tratamiento }\end{array}$ & $\mathrm{Si}$ \\
\hline Bansal et al. (14) & 2013 & India & Revisión & $\begin{array}{l}\text { Describir la evidencia } \\
\text { epidemiológica y los } \\
\text { mecanismos que apoyan } \\
\text { el papel de las bacterias } \\
\text { orales en el proceso de } \\
\text { infección respiratoria }\end{array}$ & No aplica & $\begin{array}{l}\text { La mejora de la higiene oral } \\
\text { puede reducir el riesgo de } \\
\text { infección respiratoria. El } \\
\text { tratamiento de la } \\
\text { enfermedad periodontal } \\
\text { podria ser otra forma de } \\
\text { reducir la incidencia de } \\
\text { infecciones respiratorias }\end{array}$ & $\mathrm{Si}$ \\
\hline Barros et al. (26) & 2013 & $\begin{array}{l}\text { Estados } \\
\text { Uridos }\end{array}$ & Descriptivo & $\begin{array}{l}\text { Analizar los efectos del } \\
\text { edentulismo, de la EP y } \\
\text { de los biomarcadores } \\
\text { sistémiccs de la } \\
\text { inflamación en la } \\
\text { ocurrencia de } \\
\text { acontecimientos } \\
\text { respiratorios graves } \\
\text { fatales y no mortales } \\
\text { entre los sujetos con } \\
\text { EPOC }\end{array}$ & 15.792 pacientes & $\begin{array}{l}\text { Se sugiere que el riesgo de } \\
\text { evantos relacionados con } \\
\text { EFOC despues de ajustar } \\
\text { los potenciales factores de } \\
\text { confusión puede atribuirse } \\
\text { tanto al edentulismo cono } \\
\text { a niveles elevados de II-6 } \\
\text { en suero }\end{array}$ & $\mathrm{Si}$ \\
\hline Linden et al. (58) & 2013 & $\begin{array}{l}\text { Irlanda } \\
\text { del Norte }\end{array}$ & Revisión & $\begin{array}{l}\text { Revisar la evidencia } \\
\text { sobre la asuciaciún entre } \\
\text { periodonitis y diversas } \\
\text { enfermedades sisténicas, } \\
\text { incluida EPOC }\end{array}$ & No aplica & $\begin{array}{l}\text { Se sugiere una asociación } \\
\text { entre periodontitis y EPOC } \\
\text { basada en el análisis de los } \\
\text { coajuntos de datos }\end{array}$ & $\mathrm{Si}$ \\
\hline $\begin{array}{l}\text { Bergström et al. } \\
(47)\end{array}$ & 2013 & Suecia & $\begin{array}{l}\text { Casos y } \\
\text { ccutroles }\end{array}$ & $\begin{array}{l}\text { Describir la covariación } \\
\text { de la periodontitis y el } \\
\text { deterioro de la función } \\
\text { pulmonar en fumadores }\end{array}$ & 80 pacientes & $\begin{array}{l}\text { La periodontitis se asoció } \\
\text { fuertemente con el } \\
\text { tabaquismo y débilmente } \\
\text { con la destrucción del } \\
\text { tejido pulmorar }\end{array}$ & $\mathrm{Si}$ \\
\hline Peter et al (44) & 2013 & India & $\begin{array}{l}\text { Casosy } \\
\text { ccntroles }\end{array}$ & $\begin{array}{l}\text { Determinar la asociación } \\
\text { entre enfermedad } \\
\text { periodonal y EFOC }\end{array}$ & 501 paciertes & $\begin{array}{l}\text { Aunque el presente estudio } \\
\text { no pudo determirar la } \\
\text { asociación causal, } \\
\text { proporciona pruebas } \\
\text { sustanciales que la mala } \\
\text { salud periodontal se asocia } \\
\text { con EPOC }\end{array}$ & $\mathrm{Si}$ \\
\hline $\begin{array}{l}\text { Kucukcosisun et al. } \\
(49)\end{array}$ & 2013 & Turquia & $\begin{array}{l}\text { Estudio } \\
\text { prospectivo } \\
\text { y conirolado }\end{array}$ & $\begin{array}{l}\text { Evaluar el efecto de la } \\
\text { terapia periodontal inicial } \\
\text { sobre la frecuencia de } \\
\text { exacerbación en } \\
\text { pacientes con EPOC }\end{array}$ & $\begin{array}{l}40 \text { pacientes: } 20 \\
\text { (grupo } \\
\text { intervencion) y } \\
20 \text { (gnipo } \\
\text { cortrol) }\end{array}$ & $\begin{array}{l}\text { La terapia periodantal } \\
\text { inicial en pacientes con } \\
\text { EPOC puede disminuir la } \\
\text { frecuencia de exacerbacion }\end{array}$ & $\mathrm{Si}$ \\
\hline
\end{tabular}


Anexo 1 (cont.)

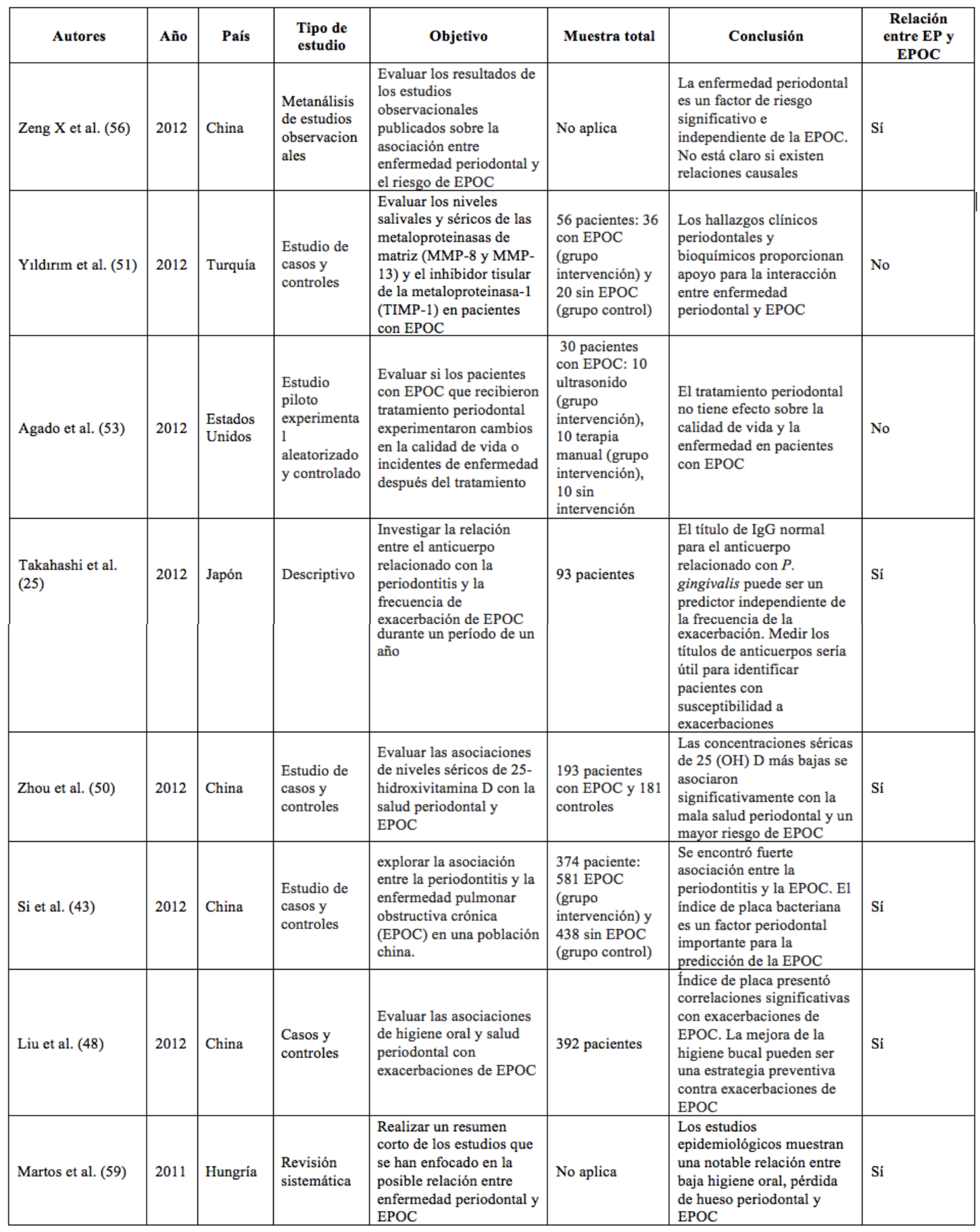




\section{Anexo 1 (cont.)}

\begin{tabular}{|c|c|c|c|c|c|c|c|}
\hline Autores & Año & Pais & $\begin{array}{l}\text { Tipo de } \\
\text { estudio }\end{array}$ & Objetivo & Muestra total & Conclusión & $\begin{array}{l}\text { Relación entre } \\
\text { EP y EPOC }\end{array}$ \\
\hline Sharma et al. (21) & 2011 & India & Descriptivo & $\begin{array}{l}\text { Determinar la asociación } \\
\text { entre enfermedad } \\
\text { periodontal y EPOC }\end{array}$ & $\begin{array}{l}200 \text { pacientes: } \\
100 \text { con EPOC } \\
\text { (grupo } \\
\text { intervención) y } \\
100 \text { sin EPOC } \\
\text { (grupo control) } \\
\end{array}$ & $\begin{array}{l}\text { Los resultados apoyan una } \\
\text { asociación entre la } \\
\text { enfermedad periodontal y } \\
\text { EPOC }\end{array}$ & Sí \\
\hline Zhou et al. (22) & 2011 & China & Descriptivo & $\begin{array}{l}\text { Evaluar la asociación de } \\
\text { la salud periodontal y los } \\
\text { parámetros de calidad de } \\
\text { vida de pacientes con } \\
\text { EPOC }\end{array}$ & 306 pacientes & $\begin{array}{l}\text { La mala salud periodontal e } \\
\text { indice de placa alto se } \\
\text { asoció significativamente } \\
\text { con menor calidad de vida } \\
\text { en pacientes con EPOC. } \\
\text { Promover el cuidado dental } \\
\text { en las estrategias actuales } \\
\text { de salud pública mejora la } \\
\text { calidad de vida en pacientes } \\
\text { con EPOC }\end{array}$ & Si \\
\hline $\begin{array}{l}\text { Leuckfeld et al. } \\
\text { (24) }\end{array}$ & 2010 & Noruega & Descriptivo & $\begin{array}{l}\text { Evaluar si las } \\
\text { propiedades o identidad } \\
\text { de la cepa de Veillonella } \\
\text { se correlacionan con } \\
\text { enfermedad periodontal y } \\
\text { EPOC }\end{array}$ & 26 pacientes & $\begin{array}{l}\text { V. parvula subgingival } \\
\text { puede trasladarse a los } \\
\text { pulmones; sin embargo, la } \\
\text { identidad o el genotipo de } \\
\text { Veillonella no se } \\
\text { correlacionaron con } \\
\text { enfermedad periodontal o } \\
\text { EPOC }\end{array}$ & No \\
\hline Deo et al. (20) & 2009 & India & Descriptivo & $\begin{array}{l}\text { Evaluar la correlación } \\
\text { entre la gravedad de } \\
\text { enfermedad periodontal y } \\
\text { EPOC }\end{array}$ & $\begin{array}{l}200 \text { pacientes: } \\
150 \text { con EPOC } \\
\text { (grupo } \\
\text { intervención) y } \\
50 \text { sin EPOC } \\
\text { (grupo control) }\end{array}$ & $\begin{array}{l}\text { El riesgo de EPOC esta } \\
\text { significativamente elevado } \\
\text { al encontrar pérdida de } \\
\text { inserción. Las } \\
\text { intervenciones orales } \\
\text { pueden reducir la gravedad } \\
\text { de EPOC }\end{array}$ & Sí \\
\hline Wang et al. (42) & 2009 & China & $\begin{array}{l}\text { Casos y } \\
\text { controles }\end{array}$ & $\begin{array}{l}\text { Evaluar la asociación } \\
\text { entre enfermedad } \\
\text { periodontal y EPOC }\end{array}$ & $\begin{array}{l}634 \text { pacientes: } \\
306 \text { con EPOC } \\
\text { (grupo } \\
\text { intervención) y } \\
328 \text { sin EPOC } \\
\text { (grupo control) } \\
\end{array}$ & $\begin{array}{l}\text { La mala salud periodontal, } \\
\text { el cuidado dental y el } \\
\text { conocimiento de la salud } \\
\text { oral se asociaron } \\
\text { significativamente con un } \\
\text { mayor riesgo de EPOC }\end{array}$ & Si \\
\hline $\begin{array}{l}\text { Leuckfeld et al. } \\
\text { (19) }\end{array}$ & 2008 & Noruega & Descriptivo & $\begin{array}{l}\text { Investigar si la } \\
\text { periodontitis es más } \\
\text { frecuente en sujetos con } \\
\text { EPOC en comparación } \\
\text { con otras enfermedades } \\
\text { respiratorias }\end{array}$ & $\begin{array}{l}275 \text { pacientes: } \\
161 \text { con EPOC } \\
\text { (grupo } \\
\text { intervención) y } \\
114 \text { sin EPOC } \\
\text { (grupo control) }\end{array}$ & $\begin{array}{l}\text { Se demostró una relación } \\
\text { significativa entre } \\
\text { periodontitis crónica y } \\
\text { EPOC, aunque } \\
\text { independiente de los } \\
\text { posibles factores de riesgo } \\
\text { para la periodontitis }\end{array}$ & Si \\
\hline $\begin{array}{l}\text { Azarpazhooh et al. } \\
\text { (15) }\end{array}$ & 2006 & Canadá & Revisión & $\begin{array}{l}\text { Investigar la asociación } \\
\text { etiológica entre la salud } \\
\text { oral y EPOC }\end{array}$ & No aplica & $\begin{array}{l}\text { Existe evidencia sobre la } \\
\text { asociación de la salud oral } \\
\text { y EPOC. La mejora de la } \\
\text { higiene oral reduce la } \\
\text { progresión o aparición de } \\
\text { EPOC en adultos mayores }\end{array}$ & Sí \\
\hline $\begin{array}{l}\text { Kowalski et al. } \\
(41)\end{array}$ & 2005 & Polonia & $\begin{array}{l}\text { casos y } \\
\text { controles }\end{array}$ & $\begin{array}{l}\text { Estimar el estado } \\
\text { periodontal en pacientes } \\
\text { con EPOC }\end{array}$ & $\begin{array}{l}201 \text { pacientes: } \\
100 \text { con EPOC } \\
\text { (grupo } \\
\text { intervención) y } \\
101 \text { sin EPOC } \\
\text { (grupo control) }\end{array}$ & $\begin{array}{l}\text { La frecuencia y severidad } \\
\text { de la enfermedad } \\
\text { periodontal da cuenta de su } \\
\text { relación de causa-efecto } \\
\text { respecto a EPOC. El } \\
\text { tratamiento de la } \\
\text { enfermedad periodontal } \\
\text { debe ser de gran } \\
\text { importancia en el } \\
\text { tratamiento de EPOC }\end{array}$ & Sí \\
\hline
\end{tabular}


Anexo 1 (cont.)

\begin{tabular}{|c|c|c|c|c|c|c|c|}
\hline Autores & Año & Pais & $\begin{array}{l}\text { Tipo de } \\
\text { estudio }\end{array}$ & Objetivo & Muestra total & Conclusión & $\begin{array}{l}\text { Relación entre } \\
\text { EP y EPOC }\end{array}$ \\
\hline Katancik et al. (18) & 2005 & $\begin{array}{l}\text { Estados } \\
\text { Unidos }\end{array}$ & Descriptivo & $\begin{array}{l}\text { Examinar la relación } \\
\text { entre la obstrucción de } \\
\text { las vías respiratorias y la } \\
\text { EP }\end{array}$ & 860 pacientes & $\begin{array}{l}\text { Revela una asociación } \\
\text { significativa entre la EP y } \\
\text { obstrucción de vías } \\
\text { respiratorias, especialmente } \\
\text { en ex fumadores. pero no se } \\
\text { puede proporcionar una } \\
\text { inferencia directa de causa } \\
\text { y efecto. }\end{array}$ & Sí \\
\hline Hyman et al. (38) & 2004 & $\begin{array}{l}\text { Estados } \\
\text { Unidos }\end{array}$ & $\begin{array}{l}\text { Cohorte } \\
\text { retrospectivo }\end{array}$ & $\begin{array}{l}\text { Comprender el papel del } \\
\text { tabaquismo en una } \\
\text { posible relación entre } \\
\text { enfermedad periodontal y } \\
\text { EPOC }\end{array}$ & 7.625 pacientes & $\begin{array}{l}\text { El tabaquismo puede ser un } \\
\text { cofactor en la relación entre } \\
\text { enfermedad periodontal y } \\
\text { EPOC }\end{array}$ & Sí \\
\hline García et al. (16) & 2001 & $\begin{array}{l}\text { Estados } \\
\text { Unidos }\end{array}$ & $\begin{array}{l}\text { Revisión } \\
\text { sistemática }\end{array}$ & $\begin{array}{l}\text { Analizar las medidas del } \\
\text { estado de salud } \\
\text { periodontal y su } \\
\text { asociación con la EPOC }\end{array}$ & No aplica & $\begin{array}{l}\text { Una relación causal entre el } \\
\text { estado de salud periodontal } \\
\text { y el riesgo de EPOC, } \\
\text { aunque biológicamente } \\
\text { plausible, sigue siendo } \\
\text { especulativa. Se requieren } \\
\text { ensayos clínicos } \\
\text { controlados aleatorizados } \\
\text { para comprender las bases } \\
\text { biológicas de las } \\
\text { asociaciones } \\
\text { epidemiológicas }\end{array}$ & Sí \\
\hline $\begin{array}{l}\text { Scannapieco et al. } \\
\text { (37) }\end{array}$ & 2001 & $\begin{array}{l}\text { Estados } \\
\text { Unidos }\end{array}$ & $\begin{array}{l}\text { Retrospectiv } \\
\text { o transversal }\end{array}$ & $\begin{array}{l}\text { Evaluar las posibles } \\
\text { asociaciones entre el } \\
\text { estado de salud oral y } \\
\text { EPOC mediante el } \\
\text { análisis de los datos de la } \\
\text { III Encuesta de } \\
\text { Evaluación Nacional de } \\
\text { la Salud y la Nutrición }\end{array}$ & 13.792 pacientes & $\begin{array}{l}\text { Los resultados del análisis } \\
\text { apoyan los informes } \\
\text { publicados recientemente } \\
\text { que sugieren una asociación } \\
\text { entre enfermedad } \\
\text { periodontal y EPOC }\end{array}$ & Sí \\
\hline Hayes et al. (17) & 1998 & $\begin{array}{l}\text { Estados } \\
\text { Unidos }\end{array}$ & Descriptivo & $\begin{array}{l}\text { Examinar si el riesgo de } \\
\text { EPOC se incrementa en } \\
\text { individuos con } \\
\text { antecedentes de EP según } \\
\text { la evaluación de la } \\
\text { pérdida ósea alveolar } \\
\text { radiográfica }\end{array}$ & 1118 pacientes & $\begin{array}{l}\text { El aumento de la pérdida } \\
\text { ósea alveolar radiográfica } \\
\text { se asocia con un mayor } \\
\text { riesgo de EPOC }\end{array}$ & Si \\
\hline
\end{tabular}

